\title{
AN INTRASPINAL DERMOID CYST ASSOCIATED WITH ANOTHER IN THE OVARY
}

\author{
BY \\ B. RAMAMURTHI and V. C. ANGULI \\ From the Neurosurgical Unit, General Hospital, Madras, and the Department of Pathology, \\ Madras Medical College, Madras
}

Dermoid cysts of the brain are not uncommon, and as many as 200 dermoid and epidermoid cysts found throughout the central nervous system have been reported by Rand and Reeves (1943). However, epidermoid and dermoid tumours of the spinal canal together with teratoid tumours, with or without communicating dermal sinuses, are of extreme rarity. Boldrey and Elvidge (1939) published a total of 43 epidermoid and dermoid cysts of the spinal cord, and in 1946 Ingraham and Bailey reported another five. Sachs and Horrax (1949) listed 59 cases and reported two more of their own, totalling 61 cases. They also published a list of 25 cases of intraspinal teratoids and teratomas, with a brief review of the literature. Moore and Walker (1951) reported a case of intraspinal epidermoid tumour. Sachs and Horrax estimated that the spinal dermoid and epidermoid tumours probably form about a quarter of the total number of those found in the central nervous system. According to Woltman, Kernohan, Adson, and Craig (1951) in their analysis of 979 intraspinal tumours, the spinal dermoid cysts form about $10 \%$ of all intraspinal neoplasms.

\section{Case Report}

R., a girl aged 19 years, was admitted on June 24, 1952 (Ref. NS 1069), with inability to walk properly, dribbling of urine, and an ulcer in the sole of the left foot.

The complaint started 10 years before with periodic attacks of pain in the small of the back which radiated forwards towards the hip. She found then that she gradually lost power in the left lower limb, which began to waste and also became numb. Six years after the onset of the first symptoms, difficulty in controlling micturition developed. A year later an ulcer developed in the sole of the foot, which persisted for three years.

On examination, she was found to be a well-nourished young girl, who walked with difficulty. The nervous system showed the following abnormalities. Both the lower limbs showed wasting of muscles with loss of power, more marked on the right side in the calf and posterior thigh muscles. The tone was diminished and all the jerks in the lower limbs were lost. There was sensory loss over the buttocks and the posterior aspect of the thighs and legs, and it was more marked on the left side with a pes cavus and perforating ulcer over the left heel. The patient also had occasional dribbling of urine with stress incontinence. Rectal examination showed a lax sphincter.

A clinical diagnosis of a tumour of the cauda equina was made.

On examination of the abdomen, a rounded, firm mass was felt in the hypogastrium, a little to the right side of the midline. The mass was mobile, and was felt to arise out of the pelvis. It did not disappear on cathet=rization. Though a dumb-bell neurofibroma involving the cauda equina and the retroperitoneal spaces was considered, the mobility of the abdominal tumour excluded this diagnosis. Vaginal examination showed the right fornix to be full while the left was free. The tumour was not felt to be attached to the uterus.

A radiograph of the lumbar spine showed destruction of the pedicles of L2 and L3 vertebrae with concavities

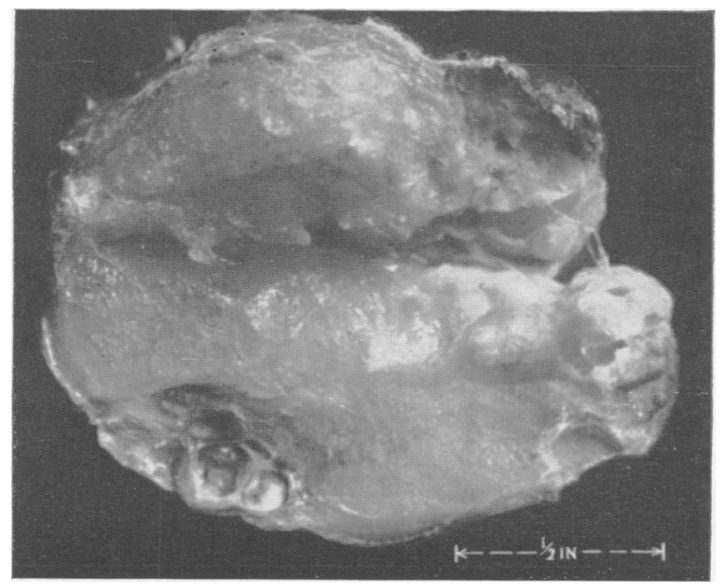

Fig. 1.-Photograph of the spinal cord tumour. A number of tiny cysts are seen towards the periphery. 
on the posterior surface of their bodies. Lumbar puncture showed clear cerebrospinal fluid with increased protein $(120 \mathrm{mg}$. per $100 \mathrm{ml}$.). Cisternal puncture was done and lipiodol injected, and showed a complete block at the level of the second lumbar vertebra.

On July 2, 1952, under general anaesthesia, the spines and laminae of the second and third lumbar vertebrae were removed. The dura was slit longitudinally in the midline and a firm tumour about 2 in. long was revealed. There were some adhesions between the dura and the capsule of the tumour. The tumour was found extending below the laminae of the fourth lumbar vertebra. The incisions were then extended, and the laminae and the spine of the fourth lumbar vertebra removed to expose the tumour completely.

The tumour was elliptical in shape with the narrower end pointing downwards (Fig. 1), and was found to arise from the filum terminale. The growth was carefully lifted off its bed from its lower end and separated from the filaments of the cauda equina. It was severed from its attachment to the cord at its upper end. The dura was stitched up completely and the wound was closed in layers.

The patient had an uneventful post-operative period and began to show signs of gradual improvement in power and control of micturition. The ulcer in the left heel healed after a month.

Pathological Report.-The gross specimen consisted of an ovoid tumour measuring 2 in. $\times \frac{3}{4}$ in. It was capsulated, felt cystic and had a pearly sheen. The cut section presented rather a compact, solid appearance. Careful examination, however, revealed a number of

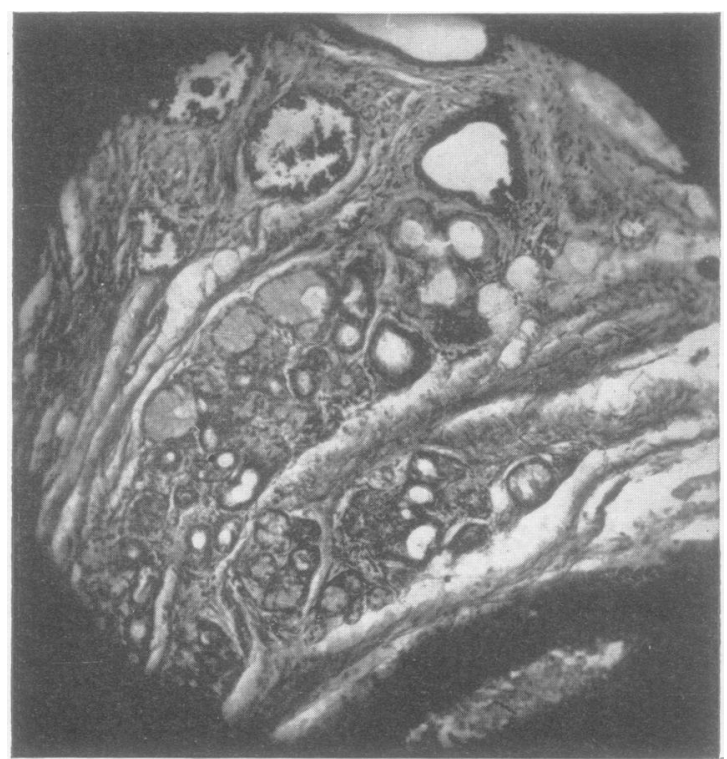

FIG. 2.-Photomicrograph of a number of small cysts; some of them containing structureless debris are seen at the top. A number of glands are grouped below. Van Gieson stain. $\times 160$.

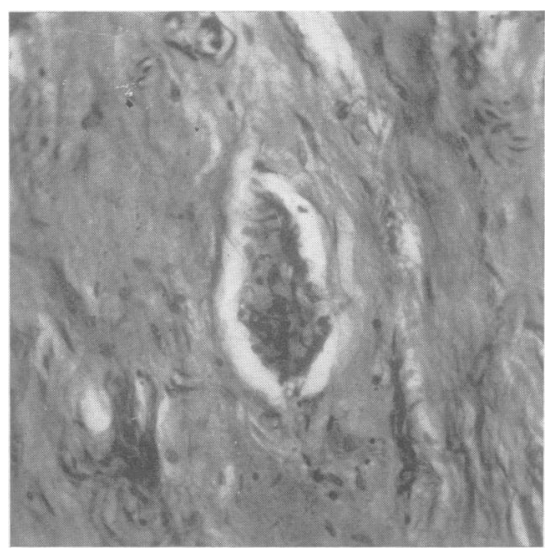

cystic spaces filled with degenerate, amorphous, caseouslike material (Fig. 2). Besides these cystic spaces were sebaceous and sweat glands in a moderately dense collagen stroma. The cysts were lined with stratified squamous epithelium, and some contained amorphous debris similar to that seen in epidermal inclusion cysts. There were no hair follicles.

The solid portions of the tumour presented a compact fibromatous background with interlacing nerve bundles and a few fat cells. In addition, there were elongated pear-shaped or elliptical structures resembling Meissner's corpuscles (Fig. 3).

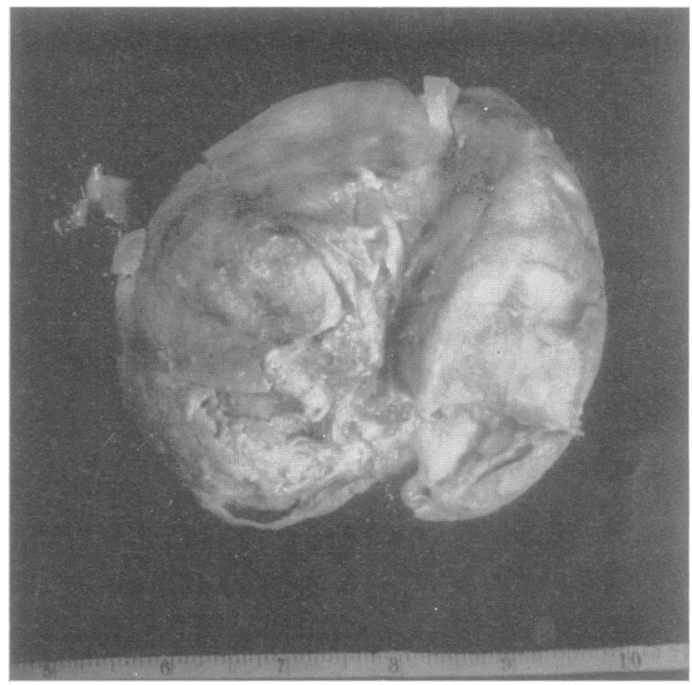

FIG. 4.-The ovarian tumour, which is a cystic globular tumour filled with strands of hair of which the fine strands are not clearly visible in the photograph. 
Except for the associated fibrolipomatous tissue background no other mesenchymal structure was found in the several sections studied, neither was there any entodermal representation.

The Ovarian Tumour.-A month later, under general anaesthesia, laparotomy was performed. A spherical tumour, 6 in. in diameter, was found arising from the right ovary. This was removed and the patient had an uneventful post-operative period. It was a large ovoid tumour with a thick, whitish, opaque wall, cystic to the touch (Fig. 4). On opening the cyst, the true nature of the tumour was revealed by an outpouring of pultaceous, greasy, sebaceous material together with abundant strands of hair. The distinctive feature under the microscope was the presence of skin tissue and its appendages in the cyst wall. In addition, there were phagocytic leucocytes and foreign body giant cells in the wall.

No other ectodermal or mesodermal structure was encountered. There was no evidence of malignancy. The tumour was a benign cystic dermoid.

\section{Summary}

A case of lumbar intraspinal dermoid cyst associated with another dermoid cyst of the ovary is reported.

From a survey of the available literature, this is the first report of such a case.

Our thanks are due to Col. Sangam Lal, Professor of Surgery, Madras Medical College, who removed the ovarian tumour, and Dr. D. Govinda Reddy, Professor of Pathology, Madras Medical College, and to the Dean, Madras Medical College, for permission to publish this paper.

\section{REFERENCES}

Boldrey, E. B., and Elvidge, A. R. (1939). Ann. Surg., 110, 273.

Ingraham, F. D., and Bailey, O. T. (1946). J. Neurosurg., 3, 511. Moore, W. W., and Walker, E. (1951). Ibid., 8, 343.

Rand, C. W., and Reeves, D. L. (1943). Arch. Surg., Chicago, 46 350. Quoted by Sachs and Horrax.

Sachs, E., and Horrax, G. (1949). J. Neurosurg., 6, 97.

Woltman, H. W. Kernohan, J. W.,Adson, A. W., and Craig, W. McK. (1951). Arch. Neurol. Psychiat., 65, 378.

\section{THE MAY (1954) ISSUE}

The May (1954) issue contains the following papers :-

Meningiomas within the Lateral Ventricle. A. E. Wall.

Ischaemic Sensory Loss in Patients with Peripheral Nerve Lesions. R. W. Gilliatt and T. Grahame Wilson.

Memory Disturbances in Third Ventricle Tumours. Moyra Williams and Joe Pennybacker.

Variations with Age in the Number of Active Palmar Digital Sweat Glands. Pamela C. B. Mackinnon.

Phosphate Esters in Myotonic Human Muscle. P. C. Caldwell and T. A. J. Prankerd.

A Rare Presenile Dementia Associated with Cortical Blindness (Heidenhain's Syndrome). A. Meyer, Denis Leigh, and C. E. Bagg.

Two Cases of Congenital Atresia of the Foramina of Magendie and Luschka. A. F. J. Maloney.

Autonomic Changes after Unilateral Leucotomy. Alick Elithorn, Malcolm F. Piercy, and Margaret A. Crosskey.

A Comparison of Isoniazid with Modified Insulin Therapy in Neurotic States. Maurice Silverman.

Rapidly Progressive Cerebral Degeneration (Subacute Vascular Encephalopathy) with Mental Disorder, Focal Disturbances, and Myoclonic Epilepsy. D. P. Jones and S. Nevin.

A number of copies are still available and may be obtained from the Publishing Manager, British Medical Association, Tavistock Square, W.C.1, price 12s. 6d. 